\title{
Parental perceptions of the informed consent process in pediatric oncology clinical trials
}

\author{
Yvonne D Hastings ${ }^{1}$, Natalie K Bradford ${ }^{1,2}$, Liane R Lockwood ${ }^{1}$, Robert S Ware ${ }^{3}$, Jeanine Young ${ }^{4}$ \\ 1. Queensland Children's Cancer Centre, Royal Children's Hospital, Brisbane, Australia. 2. Centre for Online Health, The \\ University of Queensland, Brisbane, Australia. 3. Queensland Children's Medical Research Institute, The University of \\ Queensland, Brisbane, Australia. 4. School of Nursing and Midwifery, University of the Sunshine Coast, Sippy Downs, \\ Australia.
}

Correspondence: Yvonne Hastings. Address: Queensland Children's Cancer Centre, Royal Children's Hospital, Herston Rd, Herston, QId, Australia. Telephone: 61-736-368-111. Email: Yvonne_Hastings@health.qld.gov.au.

Received: November 11, 2012

Accepted: January 29, $2013 \quad$ Online Published: April 18, 2013

DOI : 10.5430/jnep.v3n11p71

URL: http://dx.doi.org/10.5430/jnep.v3n11p71

\section{Abstract}

Background: The integrity of good clinical practice in clinical trials is underpinned by the informed consent process; however the stress of a life threatening diagnosis challenges the absorption of information and may affect the parent's ability to understand diagnosis, treatment plans and the consent process.

Aims: The aim of this study was to explore and describe parental perceptions of the informed consent process in pediatric oncology clinical trials.

Methods: A cross-sectional survey was used to collect responses from 50 parents of children aged 8-16 years, enrolled on a clinical trial, one month after diagnosis at an Australian tertiary pediatric oncology centre.

Results: The majority of parents (47, 94\%) agreed that they understood the diagnosis and information regarding the purpose of the clinical trial. Parents relied primarily on their Oncology consultant for this information. Parents discussed the diagnosis with their children although only $60 \%(n=30)$ felt that their child understood the treatment and trial process.

Conclusions: Parents indicated that the current process of providing information regarding the clinical trial process met their needs and that they were able to provide informed consent. They were unsure however, of how involved they wanted their children to be in treatment decisions.

\section{Key words}

Informed consent, Assent, Clinical trials, Pediatric oncology

\section{I ntroduction}

The incidence of childhood cancer has been slowly, but steadily rising over the last few decades. In middle and high income nations, childhood cancer remains the leading cause of death from disease from late infancy through to early adulthood $^{[1]}$. If not appropriately treated many more deaths would result as the majority of childhood cancers are uniformly fatal. Treatment for childhood cancer is, therefore, an important and relevant issue. Treatment for childhood cancer may consist of various combinations of chemotherapy, radiotherapy and surgery depending on the presenting 
disease. Often treatment protocols are developed through a clinical trial process, which involves using experimental or unproven therapy. Participation in a pediatric clinical trial requires the consenting parent to be fully informed of the clinical trial process, a requirement which lead us to pose the question:

Are the current processes for providing information to parents sufficient for parents to make informed consent for their child to participate in pediatric oncology clinical trials?

This article discusses the existing evidence on this topic and a research study that was conducted to build on that evidence by providing information regarding parental perceptions of the informed consent process.

\section{Clinical trials in pediatric oncology}

Over the last three decades, clinical trials have substantially improved event-free survival outcomes for children with cancer $^{[1]}$. Around eighty percent of children are now cured of their disease, many participating in a clinical trial as part of their therapeutic care; indeed participation in a clinical trial has demonstrated superior outcomes ${ }^{[2,3]}$. Clinical trials are therefore an important part of the treatment of childhood cancer. With an incidence of around 14 in 100,000, childhood cancer remains a rare disease. Thus, international collaboration and partnership through co-operative groups has developed as an important factor to advance knowledge in treating childhood cancers ${ }^{[2,4]}$.

\section{Parental perspectives of clinical trials}

The attitudes of parents may affect understanding and participation in clinical trials. Caldwell and colleagues (2003) explored parental attitudes towards clinical trials in a qualitative analysis of 33 parents from a pediatric teaching hospital and a local school in Australia. Parents balanced risks and benefits when deciding about their child's participation in clinical trials ${ }^{[5]}$. Perceived benefits included the offer of hope, better care for their child, the opportunity to access new treatment, meeting others in similar circumstances and helping others. Parents may also rely on their relationship with healthcare providers to assist with decision making ${ }^{[6]}$. Indeed, Woodgate and colleagues (2010) found that parents need support not only during the initial decision-making period, but throughout the time their child is enrolled in a clinical trial ${ }^{[7]}$. Eder and colleagues (2007) described seven components identified by parents that improve the process of providing consent: timing, sequence, a checklist, clarifying, anticipatory guidance, historical discussion of randomized controlled trials; and choice ${ }^{[8]}$. This finding was consistent with Truong et al, (2011) who found that parents report needing more time and opportunity for questions regarding clinical trials compared with their adult counterparts ${ }^{[9]}$. These qualitative studies have helped guide the processes of providing informed consent, however are unable to measure the effect of variables within the process.

\section{I nformed consent}

A pivotal requirement of participating in a clinical trial is compliance with ethical codes such as the 'Declaration of Helsinki' ${ }^{[10]}$ and the Australian 'National Statement on Ethical Conduct in Research involving Humans' [11]. These established codes of good clinical practice mandate that information is provided to participants to ensure an understanding of diagnosis and the treatment on a clinical trial, ensuring informed consent and assent. Each country also has specific laws that ensure these ethical codes are followed. This includes assessment of each trial by a Human Ethical Review Committee (HREC), thorough data collection, reporting of adverse events, and provision of informed consent throughout the clinical trial.

In most countries a minor comes of age at 18 years and until that time parents have a legal and moral responsibility to make medical decisions they believe to be in the child's best interest ${ }^{[12]}$. As Farnell (2003) noted, the child has a right to be treated with the best medical intervention available ${ }^{[13]}$. Informed consent, as defined by the National Health and Medical Research Council of Australia, is “A person's or group's agreement, based on adequate knowledge and understanding of relevant material, to participate in research" ${ }^{[11]}$. 
Informed consent is the cornerstone of evidenced based medical care and is a voluntary participation in research, not influenced by external coercion or inducement. Requirements of informed consent include an explanation of: the purpose

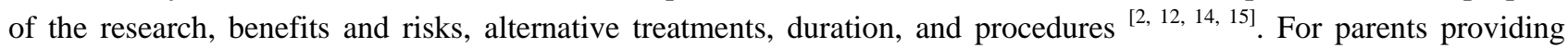
consent for their child to participate in a clinical trial, the process is dynamic and continuous throughout the child's treatment ${ }^{[16]}$. It is therefore important to understand whether the processes undertaken to obtain informed consent are sufficient to meet parental needs and expectations of the process.

\section{Assent of the child/ adolescent}

Consent and assent are not the same process. Consent requires a formal agreement to participate by a legally competent person (the parent), whereas assent refers to a child's affirmative agreement to participate in research ${ }^{\text {[15] }}$. In many countries, including the United States of America and Australia, regulations require that wherever possible children/ adolescents affirmatively agree to research participation thus providing their assent ${ }^{[17,18]}$. Joint decision-making between a child/adolescent and their parents to participate in a research trial is the optimal recommendation for obtaining assent ${ }^{[17,19]}$. This process however, also requires that the child or adolescent is considered competent to assent to treatment ${ }^{[20,21]}$.

The competency of each adolescent and child is an ever-changing process. Competency has been referred to as having certain skills that enable a person to perform in a certain manner ${ }^{[22]}$. There is recognition that many older children and adolescents are competent to receive information and to participate in therapeutic decisions about their own care ${ }^{[12,23]}$. The relevant age of competency in decision making has not been agreed upon, and this highlights the conceptual dilemmas related to developing policies and guidelines regarding consent and assent procedures for children and adolescents ${ }^{[15,18]}$.

In the pediatric oncology setting, the processes of consent and assent have the added dilemma of the diagnosis of a life threatening illness, and the requirement of the clinician to obtain parental permission prior to commencing therapeutic care ${ }^{[17,19]}$. Despite the recognition of the importance of adhering to the principles of informed consent, and the need to respect the rights and autonomy of individuals regardless of age, there is a paucity of evidence informing best practice for this process. There is a need to understand how the informed consent and assent process in the pediatric oncology setting is understood by parents of children receiving treatment as part of a research clinical trial protocol ${ }^{[9,24]}$.

In establishing our study aims we were keen to review our current practice to ensure it was effective, comprehensive and supportive of parents providing consent for their child to be enrolled in clinical trials. The primary aim of this study was to describe parental perceptions of the understanding of the diagnosis, clarity of clinical trial information received, the informed consent process and their child's understanding of the information communicated to them.

\section{Methods}

We conducted a cross-sectional questionnaire survey among parents of children and adolescents at the Oncology Center of a major tertiary children's hospital in Brisbane, Australia. This institution admits $150-180$ newly diagnosed oncology patients each year and participates in clinical trials with collaborative international organization such as the Children's Oncology Group (COG), St Jude's Children's Research Hospital in the United States, and the European based International Society of Paediatric Oncology (SIOP) group. Each year an average of 20 trials were opened following approval by the Hospital's Human Research Ethics Committee. During the study period all trials that were opened were phase III trials and under the auspices of the above collaborative groups.

\section{Questionnaire design}

A self report questionnaire was developed in line with the study aims. The investigator team that developed the questionnaire included an expert panel $(n=4)$ comprising experienced oncology clinicians and pediatric and child health 
researchers. A review of the literature identified a number of methodologies used to capture perceptions relating to informed consent from health care areas ${ }^{[8,14,25-33]}$. However, no study collected data directly relevant to the key focus of this study. Many of these studies used samples of healthy children and our research questions pertained to parents and adolescents who were required to consider multiple facets of information following a stressful and potentially life threatening diagnosis.

The questionnaire comprised 57 questions, including a demographic section $(\mathrm{n}=12)$ and questions relating to parent perception of the:

(1) information received about their child's cancer diagnosis $(n=8)$;

(2) clarity of information provided about their child's enrolment in a clinical research trial $(\mathrm{n}=10)$;

(3) informed consent process ( $\mathrm{n}=11)$;

(4) information provided to their child and their child's knowledge of the clinical trial process ( $n=16)$.

Parents were asked to indicate their level of agreement or disagreement with each statement using a 5-point Likert scale ( $1=$ strongly agree to $5=$ strongly disagree). There was also a free text comments section. The initial study of the survey questionnaire was piloted with 10 parents. A lack of clarity within the wording of questions was revealed. Each parent was then questioned face to face and the questions refined to improve clarity.

\section{Recruitment plan}

Participant inclusion criteria comprised being a parent or guardian (male or female) of a child/adolescent aged 8-16 years enrolled into a research clinical trial, one month from diagnosis. The time of one month post diagnosis was chosen to allow families time to overcome the initial trauma of the diagnosis and to have a treatment regime established. This sample was inclusive of all oncological diagnoses and children who came from an extensive geographically catchment area. Children needed to be able to consider multiple facets of information within a potentially life threatening environment and to communicate their understanding to their parents, hence the lower age limit of 8 years. The literature indicates children this age demonstrate a basic understanding of the purpose of research although may not have appropriate maturity in decision making ${ }^{[15,33,34]}$. The upper age limit was determined as a result of the policy of many pediatric units, including this Australian center, to refer children older than 16 years to adult centers.

In liaison with pediatric oncologists, a clinical nurse identified eligible participants. The nurse was not involved in the process of obtaining informed consent for enrollment on a clinical trial. The nurse and/or the participant's oncologist approached eligible parent participants and verbal explanation of the survey study was given. Written participant information detailing aims and procedures regarding the research study were provided. All potential participants were followed up at the next hospital visit, and written participant consent obtained. The questionnaire took approximately 20 minutes to complete and was collected in a sealed box available on the unit or by reply paid envelope. Questionnaires were numerically coded to allow for one reminder notice for failures to return and to maintain confidentiality. Returned surveys and consent were secured in a designated filing cabinet accessible only to the study investigators.

Approval for this study was received from the Hospital's Human Research Ethics Committee (HREC/QRCH/2006/038).

\section{Data analysis}

Descriptive statistics were calculated including frequencies and percentages for responses to each question. Questions that revealed a wide spread of answers were analyzed further by stratifying for categorical variables of participants (age of parents, age of child/adolescent, education level). After data inspection, nonparametric methods were used to test for significance where appropriate. A univariate linear regression model was used to investigate the differences in responses for explanatory demographic variables, including age and education level. Comparisons using categorical variables were 
tested using Chi-square and Fisher's Exact tests, as appropriate. Statistical analyses were performed using the statistical software 'R' 2.11.1 (The R Foundation for statistical reporting 2010-05-31). Free text comments supporting findings are presented where relevant.

\section{Results}

\section{Parent participants}

Sixty-nine eligible parents were identified, however, eight families were missed and nine families not approached by request of the pediatric oncologist. Of the 51 parents who were approached, 50 consented to participate in the study and returned completed questionnaires (98\% response rate). Demographic characteristics of participating parents and their children are presented in Table 1. The results of key findings are presented in Table 2 and discussed in more detail in the following sections.

\section{Parental perception of communication of information}

The majority of parents responded that information regarding the diagnosis, the purpose of a research clinical trial and any questions they had, were answered by the pediatric oncologist in a way that they understood.

"I felt that all was handled very well, all was explained to us and she spoke to us with respect and her guidance to help our child was amazing” (Parent of child aged 9 years)

Parents agreed they were anxious when the diagnosis of cancer was discussed with the pediatric oncologist and wanted to meet on subsequent occasions to ask further questions.

"It was such a stressful time that I couldn't take in too much information” (Parent of child aged 13 years)

The difficulty of needing to make choices about participating in a clinical trial so soon after receiving an oncology diagnosis was highlighted by one parent.

"Please clarify exactly what the illness is, in clear layman's terms taking into consideration that first week of diagnosis is a nightmare... every minute of the first week very little extra information is able to be processed clearly" (Parent of child aged 13 years)

\section{Parental perception of the informed consent process}

There was a mixed response when parents were asked if they felt more in control by signing the consent document; no demographic characteristics were associated with these response differences. Free text comments from parents revealed that more attention was needed regarding the option of receiving standard care as opposed to enrolling on a clinical trial. This was illustrated by the following quotes from two parents.

"I would have liked to have been able to see the treatment if my daughter had not been on the clinical trial. We feel we didn't have a choice because we didn't see any paperwork about the standard treatment" (Parent of child aged 13 years)

"I would have liked to have had a comparison between the standard treatments earlier, rather than having to ask for them myself a few days before the decision was needed" (Parent of child aged 9 years) 
Information presented to participating parents to read as part of the informed consent process varied from 9 to 43 pages depending on the clinical trial. These documents, though from varying sources, were developed in line with the theoretical presentation of the informed consent process, uniformly designed at a reading age of 12 years ${ }^{[16]}$.

Table 1. Characteristics of participants

\begin{tabular}{|c|c|c|}
\hline Characteristics & Number & $\%$ \\
\hline \multicolumn{3}{|l|}{ Person Completing questionnaire } \\
\hline Mother & 40 & 80 \\
\hline Father & 10 & 20 \\
\hline Total & 50 & 100 \\
\hline \multicolumn{3}{|l|}{ Age of parent (years) } \\
\hline $25-35$ & 6 & 12 \\
\hline 36-45 & 32 & 64 \\
\hline $46-55$ & 11 & 22 \\
\hline Missing & 1 & 2 \\
\hline Total & 50 & 100 \\
\hline \multicolumn{3}{|l|}{ Ethnicity } \\
\hline Caucasian/European & 42 & 84 \\
\hline Asian & 2 & 4 \\
\hline Aboriginal/Torres strait Islander & 4 & 8 \\
\hline Missing & 2 & 4 \\
\hline Total & 50 & 100 \\
\hline \multicolumn{3}{|l|}{ Highest level of Education } \\
\hline$<$ Year 10 & 3 & 6 \\
\hline Completed year 10 & 8 & 16 \\
\hline Complete year 12 & 17 & 34 \\
\hline Trade Certificate & 3 & 6 \\
\hline Tertiary qualification & 4 & 8 \\
\hline University qualification & 15 & 30 \\
\hline Total & 50 & 100 \\
\hline \multicolumn{3}{|l|}{ Gender of Child } \\
\hline Male & 28 & 56 \\
\hline Female & 22 & 44 \\
\hline Total & 50 & 100 \\
\hline \multicolumn{3}{|l|}{ Number of other children } \\
\hline 0 & 1 & 2 \\
\hline $1-2$ & 35 & 70 \\
\hline $3-4$ & 12 & 24 \\
\hline Missing & 2 & 4 \\
\hline Total & 50 & 100 \\
\hline \multicolumn{3}{|l|}{ Diagnosis of child } \\
\hline ALL & 23 & 46 \\
\hline Hodgkins Lymphoma & 5 & 10 \\
\hline Osteosarcoma & 3 & 6 \\
\hline AML & 2 & 4 \\
\hline Brain Tumour & 14 & 28 \\
\hline Neuroblastoma & 1 & 2 \\
\hline Rhabdomyosarcoma & 1 & 2 \\
\hline Wilms Tumour & 1 & 2 \\
\hline Total & 50 & 100 \\
\hline \multicolumn{3}{|l|}{ Child age at diagnosis (years) } \\
\hline 8-12 & 23 & 46 \\
\hline $13-16$ & 27 & 54 \\
\hline Total & 50 & 100 \\
\hline
\end{tabular}

Note. Mean time since diagnosis= 36 Days (range 28-58) 
Table 2. Key findings from questionnaire

\begin{tabular}{|c|c|c|c|}
\hline Statement & $\begin{array}{l}\text { Agree } \\
\mathrm{N}(\%)\end{array}$ & $\begin{array}{l}\text { Unsure } \\
\mathrm{N}(\%)\end{array}$ & $\begin{array}{l}\text { Disagree } \\
\mathrm{N}(\%)\end{array}$ \\
\hline My child's cancer diagnosis was explained to me in a way I understood & $47(94)$ & $3(6)$ & - \\
\hline All of my questions were answered in a way I understood & $47(94)$ & $2(4)$ & $1(2)$ \\
\hline I understood what a research clinical trial was & $47(94)$ & $1(2)$ & $2(4)$ \\
\hline $\begin{array}{l}\text { I wanted to meet with the oncology consultant again and ask more questions } \\
\text { about the cancer }\end{array}$ & $40(80)$ & $5(10)$ & $5(10)$ \\
\hline I talked with nursing staff about my child's cancer & $36(72)$ & $5(10)$ & $9(18)$ \\
\hline I talked with my social worker about my child's cancer & $32(64)$ & $6(12)$ & $12(24)$ \\
\hline I went onto the internet to learn more about my child's cancer & $29(58)$ & $1(2)$ & $20(40)$ \\
\hline I read books to learn more about my child's cancer & $25(50)$ & $2(4)$ & $18(26)$ \\
\hline $\begin{array}{l}\text { I understood the difference between my child entering the research clinical trial } \\
\text { and receiving standard protocol treatment }\end{array}$ & $39(87)$ & $8(16)$ & $3(6)$ \\
\hline $\begin{array}{l}\text { I understood that there were possible risks for my child entering the research } \\
\text { clinical trial }\end{array}$ & $36(72)$ & $7(14)$ & $7(14)$ \\
\hline $\begin{array}{l}\text { I understood that there were possible benefits for my child entering the research } \\
\text { clinical trial }\end{array}$ & $44(88)$ & $2(4)$ & $4(8)$ \\
\hline I understood that I could ask the hospital staff for more information at any time & $48(96)$ & $2(4)$ & - \\
\hline $\begin{array}{l}\text { I understood that I could withdraw my child from the research clinical trial at } \\
\text { any time }\end{array}$ & $49(98)$ & $1(2)$ & - \\
\hline $\begin{array}{l}\text { I felt under pressure to sign the research clinical trial consent document for my } \\
\text { child because treatment needed to begin }\end{array}$ & $6(12)$ & $5(10)$ & $39(78)$ \\
\hline $\begin{array}{l}\text { My questions were answered satisfactorily before I signed the information } \\
\text { consent document }\end{array}$ & $47(96)$ & $3(6)$ & - \\
\hline I felt I was more in control by signing the informed consent document & $17(34)$ & $19(38)$ & $14(14)$ \\
\hline I have re-read the informed consent document & $32(64)$ & $4(8)$ & $14(28)$ \\
\hline The informed consent document for the research clinical trial was too long & $12(24)$ & $14(28)$ & $24(48)$ \\
\hline
\end{tabular}

\section{Parental perception of information received by their child/ adolescent}

Most parents had wanted to (44,88\%), and did (47, 94\%), discuss the cancer diagnosis with their child or adolescent, and were happy for their child/adolescent to talk with their pediatric oncologist and nurse about the diagnosis (46, 92\%). Fourteen parents (28\%) were not sure if their child understood their cancer diagnosis, but only eight (16\%) thought their child/adolescent did not understand the serious nature of the illness.

"An information booklet aimed at children, without major technical words to assist in the explanation after leaving hospital would be good" (Parent of child aged 13years)

Thirty-three (66\%) parents discussed the specifics of the research clinical trial with their child/adolescent. Approximately one third of parents indicated their child was not competent to make decisions about participation in the research trial, with rationales of the child being too young $(14,28 \%)$ or too sick $(9,18 \%)$, being provided in decision-making. 


\section{I nfluence of child/ adolescent age on parental perception of child's understanding}

Parental perceptions of child or adolescent competence categorized by age group are presented in Table 3. Overall, thirty-two (64\%) parents responded that their child understood the treatment they would receive, although a considerable proportion were unsure $(10,30 \%)$ or felt that their child did not comprehend treatment $(8,16 \%)$. The age of the child or adolescent was significantly associated with parent perception of their child's understanding of the duration of treatment $(p=.03)$ but not with the treatment plan. Univariate analysis indicated that the older the child, the more likely parents were to discuss the diagnosis and treatment options $(p<.01)$.

Table 3. Difference in parental perception of child competence by child age group

\begin{tabular}{|c|c|c|c|c|c|c|c|}
\hline \multirow{2}{*}{ Statement } & \multicolumn{3}{|c|}{ 8-11 yr olds (n= 19) } & \multicolumn{3}{|c|}{$12-15$ yr olds $(n=31)$} & \multirow{2}{*}{$\begin{array}{l}\begin{array}{l}\text { Significance } \\
\text { of difference }\end{array} \\
\text { Fishers exact }\end{array}$} \\
\hline & Agree \% & Disagree \% & Unsure \% & Agree \% & Disagree \% & Unsure \% & \\
\hline $\begin{array}{l}\text { I discussed the research trial with } \\
\text { my child }\end{array}$ & $8(42 \%)$ & $8(42 \%)$ & $3(16 \%)$ & $24(81 \%)$ & $2(6 \%)$ & $5(13 \%)$ & $\mathrm{p}=0.01$ \\
\hline $\begin{array}{l}\text { My child was competent to make a } \\
\text { decision about participating in } \\
\text { research }\end{array}$ & $6(31 \%)$ & $10(53 \%)$ & $3(16 \%)$ & 19 (62\%) & 7 (22\%) & $5(16 \%)$ & $\mathrm{p}=0.08$ \\
\hline $\begin{array}{l}\text { My child was too young to make a } \\
\text { decision about participating in } \\
\text { research }\end{array}$ & $9(47 \%)$ & $8(42 \%)$ & $2(11 \%)$ & 20 (65\%) & $6(19 \%)$ & $5(16 \%)$ & $\mathrm{p}=0.25$ \\
\hline $\begin{array}{l}\text { My child was too sick to make a } \\
\text { decision about participating in a } \\
\text { clinical research trial }\end{array}$ & $4(21 \%)$ & $14(74 \%)$ & $1(5 \%)$ & $5(16 \%)$ & $21(68 \%)$ & $5(16 \%)$ & $\mathrm{p}=0.66$ \\
\hline $\begin{array}{l}\text { My child understood about the } \\
\text { treatment they would receive }\end{array}$ & $11(58 \%)$ & $5(26 \%)$ & $3(16 \%)$ & $21(68 \%)$ & $3(10 \%)$ & $7(22 \%)$ & $\mathrm{p}=0.37$ \\
\hline $\begin{array}{l}\text { My child understood they were to } \\
\text { be in a research trial for a number } \\
\text { of years }\end{array}$ & $11(58 \%)$ & 7 (37\%) & $1(5 \%)$ & $24(78 \%)$ & $2(6 \%)$ & $5(16 \%)$ & $\mathrm{p}=0.03$ \\
\hline $\begin{array}{l}\text { I wanted my child to be given an } \\
\text { information sheet to read }\end{array}$ & $8(42 \%)$ & $3(16 \%)$ & $8(42 \%)$ & $22(68 \%)$ & $3(10 \%)$ & $7(22 \%)$ & $\mathrm{p}=0.17$ \\
\hline $\begin{array}{l}\text { I wanted my child to be given and } \\
\text { informed assent form to sign }\end{array}$ & $5(27 \%)$ & 9 (47\%) & $5(26 \%)$ & $14(47 \%)$ & 7 (22\%) & $10(31 \%)$ & $\mathrm{p}=0.19$ \\
\hline $\begin{array}{l}\text { My child understood the } \\
\text { difference between and informed } \\
\text { consent and an informed assent } \\
\text { form }\end{array}$ & $2(11 \%)$ & $12(63 \%)$ & $5(26 \%)$ & $4(15 \%)$ & $13(41 \%)$ & $14(44 \%)$ & $\mathrm{p}=0.40$ \\
\hline
\end{tabular}

The age of the child or adolescent was not significantly related to whether parents wanted their child to be given an information sheet, an informed assent sheet to sign, or whether parents perceived that their child/adolescent understood the difference between consent and assent.

\section{Parental perception of severity of child/ adolescent illness on involvement with consent process}

Parents generally disagreed (36, 72\%) that their child/adolescent was too sick to make a decision about participating in a clinical research trial but some thought time should be given to allow the child to recover.

"My son had both hands bandaged up with cannulas and couldn't sign my forms at the time. So we explained it all to him, but he wasn't able to physically sign the form although he was happy to go ahead with it" (Parent of a child aged 13 years) 
"More time is required to process and understand the situation... also if the child is old enough wait until they are well enough to be included in decision making” (Parent of a child aged 13 years)

No explanatory variable was identified for why parents may or may not want their child to be given an information sheet to read. However, parents who believed their child was too sick to make a decision about participating in a research trial, were less likely to agree that they wanted their child to be given an informed assent form, compared to parents who did not indicate their child was too sick (4, 8\% Vs 14, 30\%).

\section{Influence of parental characteristics}

Parents who were older or had a higher level of education were more likely to agree the consent document for the research clinical trial was easy to understand; however no statistically significant associations between demographic or social variables and the outcome were identified.

\section{Discussion}

In this study, we explored the perceptions of Australian parents who had consented to their child receiving treatment through a pediatric oncology clinical trial one month post-diagnosis. Recruitment to this study took longer than anticipated because of the inclusion criteria; most childhood cancers occur in early childhood and there are not as many clinical trials available in childhood cancers in later childhood. Parental perceptions of the diagnosis, the clinical trial and the informed consent and assent process relating to their child's participation were reported. Parents indicated that the information received from their pediatric oncologist, supported by other clinical staff, was sufficient to understand their child's diagnosis. Information documents and written resources strengthened the verbal presentation by staff, but were not considered more important in achieving clarity of information. In the developed world, the majority of children with a pediatric oncology condition will enroll on a clinical trial ${ }^{[8,17,24,34-36]}$. Parents play a critical part in ensuring this treatment will be in the child's best interest ${ }^{[12,37]}$, but whether they possess a comprehensive understanding of the process involved is questionable.

Providing accessible and understandable information is an essential part of achieving an informed consent and ongoing efforts should continue to ensure the informed consent process and consent documents provide clarity relating to research trial processes for the lay population ${ }^{[32,38,39]}$. In this study we identified that parents wanted more information regarding standard treatment compared to treatment on a clinical trial. We also found parents over the age of 35 years and those with a higher level of education were more likely to agree that the consent document was easy to understand and many reported rereading the document at a later date. These findings support the recommendation, incorporated in international collaborative pediatric studies, that all consent information documents should be accessible for further review as part of the informed consent process.

The study was conducted in a specialist oncology center based in a tertiary referral pediatric hospital in a metropolitan setting; representing newly diagnosed children and their families from a catchment area involving some 4 million people across a vast geographical region. Children of participant parents reflected the full spectrum of pediatric oncology diagnoses. In responding to our questionnaire parents provided a rich resource for us to continue to improve our quality of care for families undergoing clinical trials.

Parents requested further information from their doctors, nursing staff, social workers, or accessed electronic or written resources. This finding is consistent with other reports ${ }^{[6,36,40,41]}$, and highlights the importance of all staff being fully informed and confident in their approach to providing clarity of information. Most parents also reported understanding the difference between research clinical trials in comparison to standard protocol treatment, unlike a smaller study by Kupst and colleagues ${ }^{[36]}$ in which parents reported that there had been insufficient discussion on these issues. This is considered an essential aspect of understanding clinical trials. Congruent with other studies ${ }^{[30,42]}$. Parents in this study were also more 
likely to report understanding the benefits of the treatment (88\%) rather than the risks (72\%). Parents in general appeared to find the risks an acceptable part of the importance of the clinical trial in achieving a positive treatment outcome for their child. The altruism of parents also shone through with $98 \%$ understanding that the knowledge gained would benefit other children.

The high level of understanding of a clinical research trial supports other studies that have found parents are aware of the aims and outcomes of trials ${ }^{[43]}$. The volume of oral and written information provided during the consent process has also been reported as a possible obstacle in achieving fully informed consent ${ }^{[25,32]}$, however, the majority of our parents reported a clear understanding of the information provided. Parents also reported the importance of knowing clinical staff were available for ongoing information. This supports findings from other studies that ongoing verbal information provides support and instils trust between the parent and clinical staff ${ }^{[4-46]}$.

Most parents strongly supported discussing the diagnosis with their child and encouraged them to ask questions of their pediatric consultant. This concurs with the growing body of evidence that communication with children should be conducted directly and honestly to protect and safeguard their interests, and to empower them to be involved in decision-making about their own care ${ }^{[17,47,48]}$. Participating parents' children ranged from 9 to 15 years and a child's age did influence parent perceptions of their child's competence to participate in the process of assent within a research clinical trial. This finding suggests that while many parents believe their child understands the seriousness of their disease, they were not sure that their child understood the assent process. Our study indicated that parents recognized the importance of information being provided, however fewer were sure of their child being given an assent document to sign. Parents reported differing concerns as to why this might be so; the overall perception appeared to be one of protection. Parents were more likely to discuss the diagnosis and treatment with older children although the differences between consent and assent documents were not understood by half the parents involved. This paper reports on the parental perceptions of the clinical trial process however adolescent perceptions of their decision-making within a pediatric oncology research trial, and understanding of consent and assent processes is also being reviewed.

\section{Clinical implications}

This study acknowledges the importance parents place on receiving accurate and clear information given face to face by knowledgeable staff. This highlights the necessity of clinical staff, and especially nurses, to have this knowledge ready for parents to access. Parents will ask questions and their anxiety may be heightened if answers are not clear or knowledgeable. Parent perceptions of the clinical trial process may be unclear without this constant source of support. Parental perceptions of their child's understanding of the clinical trial process indicated a need for staff to be vigilant in their support of the whole family as they come to terms with the clinical trial process. There is a clear need for nursing staff to have an understanding of the cancer diagnosis and clinical trial process and therefore systems should be in place within pediatric oncology units to ensure nurses receive the appropriate education. As a result of this study, processes within our institution have been established to ensure all nursing staff receive appropriate education to improve their skills and ability to communicate with parents regarding clinical trials throughout the treatment journey.

\section{Study strengths and limitations}

Study strengths included the generalizability of this study to pediatric oncology populations, the high consent rate to participate, and the comprehensive nature of the questionnaire design within the clinical trials arena. Study limitations included slow enrolment in clinical trials due to temporary closure of trial studies (to allow for safety monitoring), studies not being available for enrolment, or completion of required study numbers. The decision to enroll parents one month post diagnosis also resulted in some families becoming ineligible as they refused ongoing trial participation due to trial randomization at this time. Some families were missed when the research nurse was unavailable for recruitment, and 
families who did not consent to participate in a clinical trial were not included in the study population. This was a single site study with an investigator developed instrument. A pilot study was carried out for clarity, but no other psychometric testing was performed. The small number of fathers recruited $(n=10)$ did not allow comparison of male versus female parent responses. Additionally the possibility of recall bias exists, where participants were asked to recall their experiences over the previous month. The study was conducted over a number of years, with consent documents for some trials being revised during this time; however parent responses remained consistent.

\section{Conclusion}

Clinical research trials will continue to provide treatment options for children who require management for pediatric oncology conditions. Key study findings include that most parents report understanding the information provided regarding diagnosis, the clinical trial and that the consent/assent process was conducted in a way that was understandable and appropriate. It was interesting to note that despite technological advances which make information immediately accessible, most parents continued to rely heavily on clinical team members for verbal clarification of the research trial than on resources such as the electronic media. Involving their child in discussions about the diagnosis and treatment was effected by the age of their child; however parents often remained ambivalent about their child's involvement, particularly in regards to signing a research assent document.

To achieve informed consent and optimal outcomes for children receiving oncology treatment via a clinical trial the healthcare team must actively involve parents in decision-making by listening and providing clear and ongoing information support throughout their treatment journey.

\section{Acknowledgments}

This study would not have been possible without the support of families of the children cared for by this center. We would also like to thank the Australian and New Zealand Hematology/Oncology Group for their grant which allowed the conduct of this study.

\section{References}

[1] Robison LL, Armstrong GT, Boice JD, Chow EJ, Davies SM, Donaldson SS, Green DM, Hammond S, Meadows AT, Mertens AC: The childhood cancer survivor study: A National cancer institute-supported resource for outcome and intervention research. Journal of Clinical Oncology. 2009; 27: 2308-2318. PMid:19364948 http://dx.doi.org/10.1200/JCO.2009.22.3339

[2] Kaatsch P: Epidemiology of childhood cancer. Cancer treatment reviews. 2010; 36: 277-285. PMid:20231056 http://dx.doi.org/10.1016/j.ctrv.2010.02.003

[3] Bleyer A: The Quid Pro Quo of pediatric versus adult services for older adolescent cancer patients. Pediatric blood \& cancer. 2010; 54: 238-241. PMid:19813248

[4] Ravindranath Y, Wagner HP, Masera G, Baez F, Veerman AJP, Cloos J, Ribeiro R, Reaman GH: Improved Outcome for Children with Acute Leukemia: How to Address Global Disparities. Childhood Leukemia. 2011: 305-322.

[5] Caldwell PHY, Butow PN, Craig JC: Parents' attitudes to children's participation in randomized controlled trials. The Journal of pediatrics. 2003; 142: 554-559. PMid:12756389 http://dx.doi.org/10.1067/mpd.2003.192

[6] Simar R, Johnson V: Pediatric Informed Consent, challenges for investigators. Applied Clinical Trials. $2002 ; 11$.

[7] Woodgate RL, Yanofsky RA: Parents' experiences in decision making with childhood cancer clinical trials. Cancer Nursing. 2010; 33: 11. PMid:19926980 http://dx.doi.org/10.1097/NCC.0b013e3181b43389

[8] Eder ML, Yamokoski AD, Wittmann PW, Kodish ED: Improving informed consent: suggestions from parents of children with leukemia. Pediatrics. 2007; 119: e849-e859. PMid:17403829 http://dx.doi.org/10.1542/peds.2006-2208

[9] Truong TH, Weeks JC, Cook EF, Joffe S: Outcomes of informed consent among parents of children in cancer clinical trials. Pediatric Blood Cancer. 2011; 57: 998-1004. PMid:21280199 http://dx.doi.org/10.1002/pbc.22983

[10] Rickham P: Human experimentation. Code of Ethics of the World Medical Association. Declaration of Helsinki. British Medical Journal. 1964; 2: 177. PMid:14150898 http://dx.doi.org/10.1136/bmj.2.5402.177 
[11] National Statement on Ethical Conduct in Research involving Humans [Internet]. 2007; Available from: http://www.nhmrc.gov.au/_files_nhmrc/publications/attachments/e72_national_statement_nhmrc_arc.pdf

[12] Kodish E: Informed consent for pediatric research: Is it really possible? The Journal of pediatrics. 2003; 142: 89. PMid:12584521 http://dx.doi.org/10.1067/mpd.2003.64

[13] Farnell SM: Commentary on the SIOP report—valid informed consent and participative decision making in children with cancer and their parents. Medical and pediatric oncology. 2003; 41: 169-170. PMid:12825230 http://dx.doi.org/10.1002/mpo.10327

[14] Annas GJ: Globalized clinical trials and informed consent. New England Journal of Medicine. 2009; 360: $2050-2053$. PMid:19439740 http://dx.doi.org/10.1056/NEJMp0901474

[15] Davidson AJ, O'Brien M: Ethics and medical research in children. Paediatric anaesthesia. 2009; 19: 994-1004. PMid:19709376 http://dx.doi.org/10.1111/j.1460-9592.2009.03117.x

[16] Sammons H: Ethical issues of clinical trials in children: a European perspective. Archives of disease in childhood. 2009; 94: 474-477. PMid:19208673 http://dx.doi.org/10.1136/adc.2008.149898

[17] Unguru Y, Sill AM, Kamani N: The experiences of children enrolled in pediatric oncology research: implications for assent. Pediatrics. 2010; 125: e876. PMid:20351001 http://dx.doi.org/10.1542/peds.2008-3429

[18] ARACY. NSWCCYP: Involving children and young people in research: a compendium of papers and reflection from a think tank co-hosted by the Australian Research Alliance for Children and Youth and the NSW Commission for Children and Young People on 11 November 2008. In Book Involving children and young people in research: a compendium of papers and reflection from a think tank co-hosted by the Australian Research Alliance for Children and Youth and the NSW Commission for Children and Young People on 11 November 2008. (Editor); 2009.

[19] Rossi WC, Reynolds W, Nelson RM: Child assent and parental permission in pediatric research. Theoretical medicine and bioethics. 2003; 24: 131-148. PMid:12943268 http://dx.doi.org/10.1023/A:1024690712019

[20] De Lourdes Levy M, Larcher V, Kurz R: Informed consent/assent in children. Statement of the Ethics Working Group of the Confederation of European Specialists in Paediatrics (CESP). European journal of pediatrics. 2003; 162: 629-633. PMid:12884032 http://dx.doi.org/10.1007/s00431-003-1193-z

[21] Children's Oncology Group, Assent Task Force. Guidelines for involving children in decision-making about research participation [Internet]. Available from: https://members.childrensoncologygroup.org/_files/AssentGuidelines/COGAssentGuidelines.pdf

[22] Miller VA, Drotar D, Kodish E: Children's competence for assent and consent: a review of empirical findings. Ethics \& behavior. 2004; 14: 255-295. PMid:15875339 http://dx.doi.org/10.1207/s15327019eb1403_3

[23] Bailly D: Issues related to consent to healthcare decisions in children and adolescents. Arch Pediatrics. 2010 ; 17 Suppl 1: S7-15. http://dx.doi.org/10.1016/S0929-693X(10)70003-8

[24] Stepan KA, Gonzalez AP, Dorsey VS, Frye DK, Pyle ND, Smith RF, Throckmorton TA, Villejo LA, Cantor SB: Recommendations for enhancing clinical trials education: a review of the literature. Journal of cancer education: the official journal of the American Association for Cancer Education. 2011; 26: 64-71.

[25] Levi RB, Marsick R, Drotar D, Kodish ED: Diagnosis, disclosure, and informed consent: learning from parents of children with cancer. Journal of pediatric hematology/oncology. 2000; 22: 3. PMid:10695815 http://dx.doi.org/10.1097/00043426-200001000-00002

[26] Truong TH, Weeks JC, Cook EF, Joffe S: Outcomes of informed consent among parents of children in cancer clinical trials. Pediatric blood \& cancer. 2011; 57: 998-1004. PMid:21280199 http://dx.doi.org/10.1002/pbc.22983

[27] Ondrusek N, Abramovitch R, Pencharz P, Koren G: Empirical examination of the ability of children to consent to clinical research. Journal of Medical Ethics. 1998; 24: 158. PMid:9650109 http://dx.doi.org/10.1136/jme.24.3.158

[28] Tait AR, Voepel-Lewis T, Malviya S: Do they understand? (part I): parental consent for children participating in clinical anesthesia and surgery research. Anesthesiology. 2003; 98: 603. PMid:12606901 http://dx.doi.org/10.1097/00000542-200303000-00005

[29] Tait AR, Voepel-Lewis T, Malviya S: Do they understand?(part II): assent of children participating in clinical anesthesia and surgery research. Anesthesiology. 2003; 98: 609. PMid:12606902 http://dx.doi.org/10.1097/00000542-200303000-00006

[30] Wiley Frances M, Ruccione K, Moore Ida M, McGuire-Cullen P, Fergusson J, Waskerwitz Mary J, Perin G, Ge J, Sather Harland N, For the Children's Cancer G: Parents' Perceptions of Randomization in Pediatric Clinical Trials. Cancer Practice. 1999; 7: 248-256. http://dx.doi.org/10.1046/j.1523-5394.1999.75010.x

[31] Gattuso J, Hinds P, Tong X, Srivastava K: Monitoring child and parent refusals to enrol in clinical research protocols. Journal of advanced nursing. 2006; 53: 319-326. PMid:16441537 http://dx.doi.org/10.1111/j.1365-2648.2006.03724.x

[32] Simon C, Eder M, Raiz P, Zyzanski S, Pentz R, Kodish ED: Informed consent for pediatric leukemia research. Cancer. 2001; 92: 691-700. http://dx.doi.org/10.1002/1097-0142(20010801)92:3<691::AID-CNCR1372>3.0.CO;2-4

[33] Broome ME: Consent (assent) for research with pediatric patients. Seminars in Oncology Nursing. 1999; 15: 96-103. http://dx.doi.org/10.1016/S0749-2081(99)80067-9 
[34] Sterling CM, Walco GA: Protection of children's rights to self-determination in research. Ethics \& behavior. 2003; $13: 237-247$. PMid:14680002 http://dx.doi.org/10.1207/S15327019EB1303_03

[35] de Vries MC, Wit JM, Engberts DP, Kaspers GJL, van Leeuwen E: Pediatric oncologists' attitudes towards involving adolescents in decision-making concerning research participation. Pediatric blood \& cancer. 2010; 55: 123-128. PMid:20486177

[36] Kupst MJ, Patenaude AF, Walco GA, Sterling C. Clinical trials in pediatric cancer: parental perspectives on informed consent. Journal of pediatric hematology/oncology. 2003; 25: 787. PMid:14528101 http://dx.doi.org/10.1097/00043426-200310000-00009

[37] Kunin H: Ethical issues in pediatric life-threatening illness: Dilemmas of consent, assent, and communication. Ethics \& behavior. 1997; 7: 43-57. PMid:11654857 http://dx.doi.org/10.1207/s15327019eb0701_4

[38] Angiolillo A, Simon C, Kodish E, Lange B, Noll R, Ruccione K, Matloub Y: Staged informed consent for a randomized clinical trial in childhood leukemia: impact on the consent process. Pediatric blood \& cancer. 2004; 42: 433-437. PMid:15049015 http://dx.doi.org/10.1002/pbc.20010

[39] Barfield RC, Church C: Informed consent in pediatric clinical trials. Current opinion in pediatrics. 2005; 17: 20. PMid:15659958 http://dx.doi.org/10.1097/01.mop.0000145718.77939.b1

[40] Ruccione K: The legacy of pediatric oncology nursing in advancing survivorship research and clinical care. Journal of Pediatric Oncology Nursing. 2009; 26: 255. PMid:19837956 http://dx.doi.org/10.1177/1043454209343179

[41] McKenna K, Collier J, Hewitt M, Blake H: Parental involvement in paediatric cancer treatment decisions. European journal of cancer care 2010; 19:621-630. PMid:19807776 http://dx.doi.org/10.1111/j.1365-2354.2009.01116.x

[42] Tait AR, Voepel Lewis T, Robinson A, Malviya S: Priorities for disclosure of the elements of informed consent for research: a comparison between parents and investigators. Pediatric Anesthesia. 2002; 12: 332-336. PMid:11982841 http://dx.doi.org/10.1046/j.1460-9592.2002.00851.x

[43] Vitiello B, Aman MG, Scahill L, McCracken JT, McDougle CJ, Tierney E, Davies M, Arnold LE: Research knowledge among parents of children participating in a randomized clinical trial. Journal of the American Academy of Child \& Adolescent Psychiatry. 2005; 44: 145-149. PMid:15689727 http://dx.doi.org/10.1097/00004583-200502000-00006

[44] Tait AR, Voepel-Lewis T, Malviya S, Philipson SJ: Improving the readability and processability of a pediatric informed consent document: effects on parents' understanding. Archives of Pediatrics and Adolescent Medicine. 2005; 159: 347. PMid:15809387 http://dx.doi.org/10.1001/archpedi.159.4.347

[45] Stewart JL, Pyke-Grimm KA, Kelly KP: Parental treatment decision making in pediatric oncology. In. Elsevier. 2005: 89-97.

[46] Massimo LM, Wiley TJ: From informed consent to shared consent: A developing process in pediatric oncology. Psycho-oncology (Chichester, England). 2004; 13: S15-S15.

[47] Vernon B, Welbury J: Consent for the examination or treatment of teenagers. Current Paediatrics. 2002; 12: 458-462. http://dx.doi.org/10.1054/cupe.2002.0332

[48] Albrecht TL, Franks MM, Ruckdeschel JC: Communication and informed consent. Current opinion in oncology. 2005 ; $17: 336$. PMid:15933463 http://dx.doi.org/10.1097/01.cco.0000166654.23169.a2 